\title{
Influence of the beam oscillation pattern and oscillation frequency on the temperature field in laser brazing with keyhole formation
}

\author{
I. Henze ${ }^{1}$ (D) $\cdot$ P. Woizeschke ${ }^{1}$ (D) \\ Received: 30 April 2020 / Accepted: 16 September 2020 / Published online: 4 October 2020 \\ (C) The Author(s) 2020
}

\begin{abstract}
Laser keyhole brazing is an opportunity to increase the process efficiency in laser brazing processes. Using small spot sizes increases the intensity and leads to the formation of a vapour capillary (keyhole) in the brazing material when a material-specific threshold value is exceeded. Due to multiple reflections/absorptions of the laser beam in the keyhole, the process efficiency increases in comparison with conventional brazing processes with single Fresnel absorption on the surface, especially when using high-reflectivity braze materials, such as aluminium-based or copper-based alloys. The energy must be distributed adequately by applying beam oscillation transversal to the brazing direction. In laser brazing processes, the temperature field in the interface between brazing and substrate material is a major factor. To analyse the effect of beam oscillation, it is assumed in this study that the temperature distribution at the surface of the melt pool is a suitable approximation for the temperature distribution at the interface to the substrate. Two key parameters are defined to quantify the temperature field referring to the homogeneity: the temporal local temperature-time curve and the temperature distribution transverse to the brazing direction. While the oscillation frequency influences the first mentioned parameter by decreasing the time interval between the local laser passes, the oscillation pattern affects the second parameter by adjusting the local actual beam velocity and its consistency.
\end{abstract}

Keywords Joining $\cdot$ Laser brazing $\cdot$ Beam oscillation $\cdot$ Temperature measurement

\section{Introduction}

Laser brazing offers the ability to join different materials with good visual quality. The joint is achieved by the wetting of a preheated substrate material with a molten brazing material. Conventional laser brazing processes use large spot sizes of several millimetres to realise the process, based on a single Fresnel absorption of the laser beam [1]. Frequently used brazing materials are aluminium and copper. These materials are highly reflective, leading to a low absorption of the laser beam and low process efficiencies [2].

A concept derived from laser welding offers the opportunity to increase the absorption, whereby decreasing the laser spot leads to an intensity that is high enough for the local evaporation of the metal (threshold intensity). A vapour

I. Henze

henze@bias.de

1 BIAS - Bremer Institut für angewandte Strahltechnik GmbH, Klagenfurter Str. 5, 28359 Bremen, Germany capillary called a keyhole is formed, in which the laser beam is absorbed multiple times, thereby increasing the efficiency [3]. The energy input into the material is done localised in the keyhole and distributed by heat conduction and convection [4]. The high absorption of the laser beam and the localised energy input result in a high temperature gradient in the vicinity of the keyhole [5]. The laser power needed for the evaporation of the metal decreases with decreasing spot size. The keyhole process has been successfully transferred to the brazing process in preliminary investigations [6]. The preheating of the substrate, which is favourable for the process by increasing the wetting time [7], is realised by heat conduction from the overheated molten brazing material when the molten brazing material wets the substrate surface.

The keyhole depth is multiple times higher than its opening diameter. In laser welding, this characteristic is used to increase the welding depth [8]. In laser brazing processes, the melt pool depth, and therefore the keyhole depth, is limited by the substrate material. Combining the high aspect ratio of the keyhole shape with the round shape of the wire (brazing material) results in a welding through in the middle of the brazing material and an incomplete melting of the edges (cf. Fig. 1, 


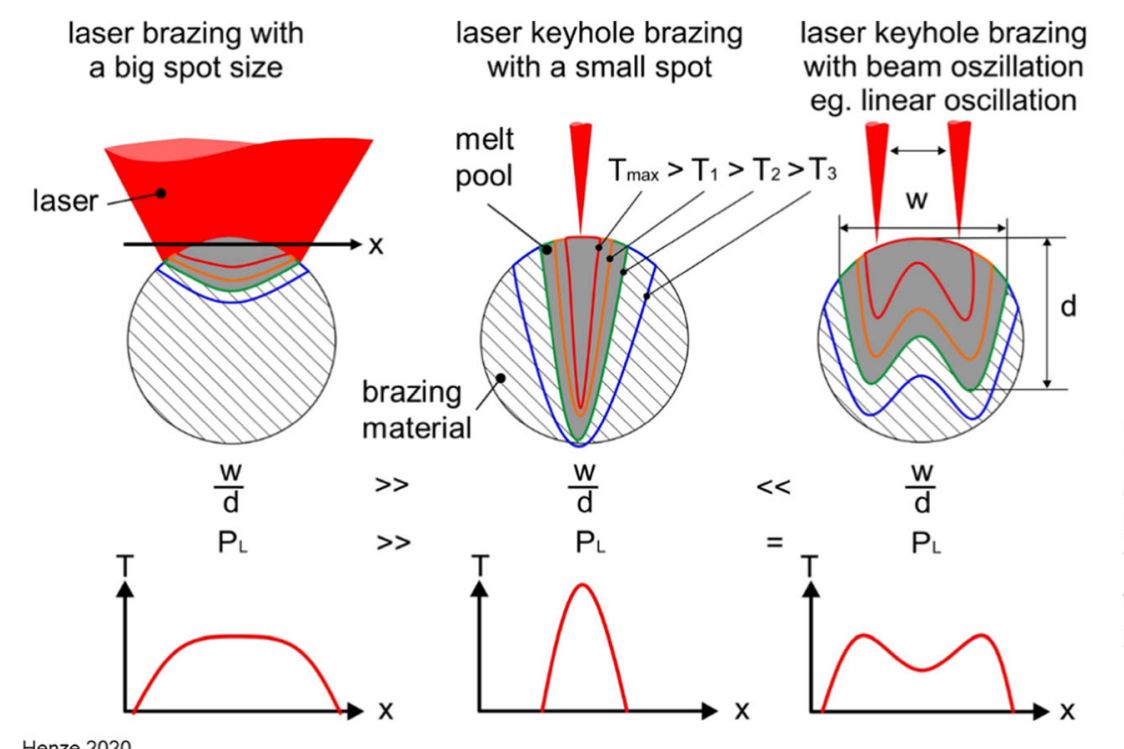

legend:

d melting pool depth

$P L$ laser power

$\mathrm{T}$ temperature

w melting pool width

$x$ position across the

melting pool surface

Henze 2020

BIAS ID 200296

Fig. 1 Effects of the keyhole formation on the melt pool depth and temperature gradients in the melting of wire-shaped material. The brazing material is not completely melted in the pictures to point out the influence of the process strategies onto the melt pool shape

middle). Heat conduction results in a wider melt pool as the keyhole width, but the widening is not sufficient for a complete melting of the wire without melting of the substrate when using small spot sizes as in this investigation. By oscillating the laser beam using a beam scanning system, the intensity can be distributed over a wider area without increasing the laser power [9]. This decreases the melt pool depth, increases the melt pool width and facilitates an efficient laser brazing process with a complete melting of the brazing material yet without melting the substrate material [6].

In laser brazing processes, the temperature field at the interface between the brazing and substrate materials is important for the joint quality. Homogenous and stationary temperature fields are regarded as the ideal process state [10]. Especially, when using brazing and substrate materials with only slight differences between the melting temperatures, these properties are essential to prevent molten areas in the substrate material. Figure 1 shows the expected temperature profiles in the brazing material wire for different spot sizes and in comparison, to the linear oscillation of the keyhole. The temperature distribution of a large spot is expected to be more homogeneous than that of the others. For the considered process, it is important to understand the influence of using the deep penetration effect in combination with beam oscillation onto the temperature field in the interface referring to the homogeneity.

The temperature profile on top of the seam is regarded as a suitable indicator of the temperature field in the interface [11]. An often used possibility to measure the temperature field in dynamic processes is infrared thermography [12]. In welding processes, it can be used, e.g. for an online adaption of the weld parameters [13] or to identify and locate welding defects [14]. The main advantages of the process are the contactless, time-resolved and geometry-independently measurements [15]. Therefore, it is an effective method for real-time monitoring of objects and processes without disturbing [12]. This method is based on the detection of an object's emitted thermal radiation, which is conditional on the emissivity, which itself is dependent on the temperature, the surface condition and the physical state [11]. Conventional infrared pyrometer measures in a spectral range of $780 \mathrm{~nm}$ to $1 \mathrm{~mm}$ [16] and a temperature range from 20 to $1700^{\circ} \mathrm{C}$ [12]. The emissivity of the detected object is a challenging factor in infrared thermography. The influence can be reduced by using, e.g. a ratio pyrometer (two-colour pyrometer) which is mostly independent of the emissivity [16]. For measurements in the constant liquid phase, the assumption of a constant emissivity is generally feasible. However, this is not the case for solid materials [17]. Another challenge is the influence of the ambient temperature which can only be neglected for high differences between the measured and the ambient temperature [16].

Further investigations into the laser brazing process with keyhole formation have shown that the oscillation parameters influence the maximum temperature as well as the occurrence of molten areas in the substrate by varying the average beam velocity [18]. In addition, investigations with respect to different oscillation patterns have demonstrated an influence on the local intensity distribution [19]. Linear oscillations have turning points that result in varying beam velocities across the movement, thus causing varying intensities and temperatures in the melt pool. These varying temperatures can cause local overheating in the turning points (cf. Fig. 1) which can lead to molten areas in the substrate material. Circular oscillation patterns, which have constant beam velocities (if neglecting the influence of the feed rate) and thus constant intensities, are probably more suitable for the formation of homogenous 
temperature fields in the melt pool. The oscillation frequency also affects the temperature distribution by changing the number as well as the time interval of the laser passes. Higher frequencies result in multiple local laser passes, which can increase the homogeneity of the temperature field. Therefore, the influence of different oscillation patterns and different oscillation frequencies on the local temperature distribution on top of the weld pool shall be investigated in this study. The resulting temperature fields are evaluated regarding to their homogeneity.

\section{Experimental}

The experiments were carried out using a single-mode fibre laser (IPG YLR-1000-SM) and a two-dimensional laser scanning system (Scanlab WelDYNA). The focal diameter was 34 $\mu \mathrm{m}$. The brazing material was an AlSi12 aluminium alloy wire with a diameter of $1.2 \mathrm{~mm}$, and the substrate material

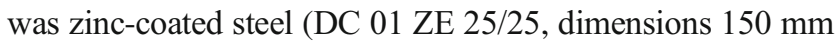
$\times 35 \mathrm{~mm}$ ) with a thickness of $1.0 \mathrm{~mm}$. The melting temperature of AlSi12 is $580{ }^{\circ} \mathrm{C} \mathrm{e}[1]$, and the melting temperature of DC 01 is $1452{ }^{\circ} \mathrm{C}$ [20]. The experiments are carried out as bead-on-plate brazing tests (brazing material application on a flat substrate) as illustrated in Fig. 2. The focal position perpendicular to the substrate surface was set in the middle of the wire. The wire angle was $45^{\circ}$. The shielding gas argon covered the process zone with a flow rate of $7.0 \mathrm{l} / \mathrm{min}$. Table 1 shows the experimental conditions and the adjusted brazing parameters. Three different oscillation patterns were applied with different characteristics. The circular movement had a constant beam velocity whereas the line and eight-shaped movement had turning points which resulted in varying velocities across the movement.

The temperature measurements were carried out with a line pyrometer (DIAS Pyroline HS 512N) with a maximum measurement frequency of $2048 \mathrm{~Hz}$. The pyrometer measures in a temperature range of 650 to $1500{ }^{\circ} \mathrm{C}$ with a 512-pixel line sensor. The applied optic had an angle of aperture of $9^{\circ} \times$ $0.04^{\circ}$. The position of the measurement line was transversal to the brazing direction with an angle of $45^{\circ}$. The distance between the seam and the pyrometer was $500 \mathrm{~mm}$. The measuring frequency was set to the maximum frequency of 2048 $\mathrm{Hz}$. Figure 3 shows the setup for the temperature measurements. For each parameter set, three samples were analysed. The emissivity of the measurements was set to a value of 0.3 , which is the emissivity for molten aluminium at $800{ }^{\circ} \mathrm{C}$ [21]. This was possible because the pyrometer only detected those molten areas in which the emissivity could be regarded as constant [17].

The temperature measurements $T_{\mathrm{M}, \mathrm{i}}$ were evaluated using the Pyrosoft Professional software (version 2017) by DIAS Infrared Systems GmbH. First, an area of interest in $\mathrm{x}$ - and time direction was defined according to the maximum measured temperature $T_{\mathrm{M} \text {,max,i }}$ of each entire measurement $i$ for $i=$ 1n ( $n$ : number of samples; in this investigation $n=3$ per parameter set). The area had a length of $150 \mathrm{~ms}$ in time direction starting $50 \mathrm{~ms}$ before $T_{\mathrm{M} \text {,max,i }}$ and a width of $2.4 \mathrm{~mm}$ in every $\mathrm{x}$-direction defined in dependence of the seam width of the samples. Using MATLAB, a compensation polynomial $T_{\text {poly }}(\mathrm{t})_{i}$ was fitted into the local measured temperature-time curve $T_{\mathrm{M}}(\mathrm{t})_{\mathrm{i}}$ in the melt pool for every x-position (cf. Fig. 4). A polynomial temperature-time curve with an increasing progression until a maximum value and then falling progression of the temperature without fluctuations is assumed as the ideal curve because it means a steady temperature-time curve where the maximum values are predictable and adjustable according to the melting temperature of the substrate material.

Secondly, the maximum value of the compensation polynomial $T_{\text {max,poly }}(\mathrm{x})_{\mathrm{i}}$ and the mean square deviation $T_{\mathrm{MSD}}(\mathrm{x})_{\mathrm{i}}$ between the temperature-time curve and the polynomial were calculated for each $\mathrm{x}$-position. Figure 4 presents an example for the evaluation of the local temperature-time curve with the equation used for the calculation of the mean square deviation.

Thirdly, the ratios of the maximum values (temperature ratio $\left.R_{\text {quo }}(x)_{\mathrm{i}}\right)$ of the polynomials $T_{\text {max,poly }}(x)_{\mathrm{i}}$ and the maximum value of all polynomials $T_{\text {max,poly,i }}(\mathrm{cf}$. Eq. 1) were cal-

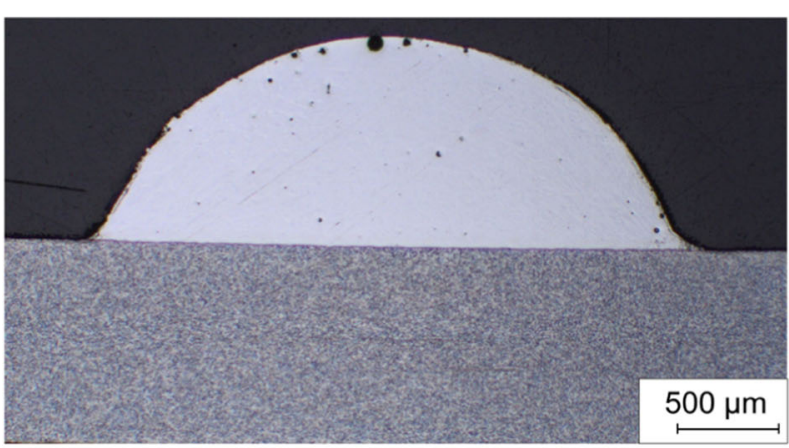

Henze 2020 laser

scanoptik

focal diameter

laser power

brazing velocity

wire material

substrate (thickness)

shielding gas

wire velocity

oscillation frequency

oscillation width

oscillation strategy
IPG YLR-1000-SM

SCANLAB weIDYNA (2D)

$34 \mu \mathrm{m}$

$470 \mathrm{~W}$

$1.0 \mathrm{~m} / \mathrm{min}$

AISi12 $(\varnothing 1.2 \mathrm{~mm})$

DC 01 ZE 25/25 (1 mm)

Argon

$1.8 \mathrm{~m} / \mathrm{min}$

$200 \mathrm{~Hz}$

$1.2 \mathrm{~mm}$

line

BIAS ID 200307

Fig. 2 Microsection of a bead-on-plate brazing seam brazed with superimposed linear beam oscillation 
Table 1 Experimental conditions and brazing parameters (varied parameters are marked in bold)

\begin{tabular}{|c|c|c|c|}
\hline Laser source & IPG YLR-1000-SM & Pyrometer & DIAS Pyroline HS 512N \\
\hline Scanoptic & Scanlab welDYNA & Measuring frequency & $2048 \mathrm{~Hz}$ \\
\hline Focal diameter & $34 \mu \mathrm{m}$ & Adjusted emissivity & 0.3 \\
\hline Substrate (thickness) & DC 01 ZE 25/25 (1 mm) & Oscillation pattern & Line, circle, eight-shaped \\
\hline Wire & AlSi 12 (Ø $1.2 \mathrm{~mm})$ & Oscillation width & $1.2 \mathrm{~mm}$ \\
\hline Shielding gas & $\mathrm{Ar}$ & Frequency & $100 \mathrm{~Hz}, 200 \mathrm{~Hz}, 300 \mathrm{~Hz}$ \\
\hline $\begin{array}{l}\text { Laser power } \\
\text { Brazing speed }\end{array}$ & $\begin{array}{l}470 \mathrm{~W} \\
1.0 \mathrm{~m} / \mathrm{min}\end{array}$ & & \\
\hline Wire speed & $1.8 \mathrm{~m} / \mathrm{min}$ & & \\
\hline
\end{tabular}

culated and plotted as a function of the x-position (cf. Fig. 5). The $\mathrm{x}$-position of the maximum measured temperature $T_{\mathrm{M} \text {,max,i }}$ of the entire temperature measurements of each sample was set as origin of the $x$-axis $(x=0)$.

$R_{\text {quo }}(x)_{i}=\frac{T_{\text {max }, \text { poly }}(x)_{i}}{T_{\text {max }, \text { poly }, i}}$

The measurements were evaluated separately and combined to calculate the average temperature ratio $R_{\text {quo }}(x)$ and the average mean square deviation $T_{\mathrm{MSD}}(x)$ as well as the average temperature ratio $\overline{R_{\text {quo }}}$ and the average mean square deviation $\overline{T_{\mathrm{MSD}}}$ across a defined area $x_{1}$ of the x-position for the different parameter sets. Table 2 shows an overview of the different steps of the evaluation of the temperature measurements.

\section{Results}

Figure 6 shows the local temperature-time curve for a reference sample without laser beam oscillation. The temperature- time curve shows a stationary temperature field with maximum temperatures in the middle of the melt pool. The temperature decreases towards the edge of the melt pool. The presented temperature-time curve is located across the $\mathrm{x}$ - value of the maximum temperature of the entire measurement $T_{\mathrm{M} \text {,max,i }}$. It presents a homogenous curve with temperature deviations up to $100 \mathrm{~K}$. The mean square deviation of the temperature-time curve and the polynomial is $83 \mathrm{~K}$.

Figure 7 presents typical temperature-time curves resulting for the three different oscillation patterns at an oscillation frequency of $200 \mathrm{~Hz}$ and an oscillation width of $1.2 \mathrm{~mm}$ (oscillation amplitude $0.6 \mathrm{~mm}$ ). The position of the maximum measured temperature is marked by a black cross in the temperature measurement. The maximum temperatures of the circular oscillation pattern are lower than those for the linear and eight-shaped oscillations. All measurements show repetitive local temperature fluctuations visible as different coloured regions in the temperature-time curve. The circular movement has the longest temporal expansion of red and green areas, whereas the linear oscillation pattern has the shortest. The local temperature of the circular oscillation pattern fluctuates

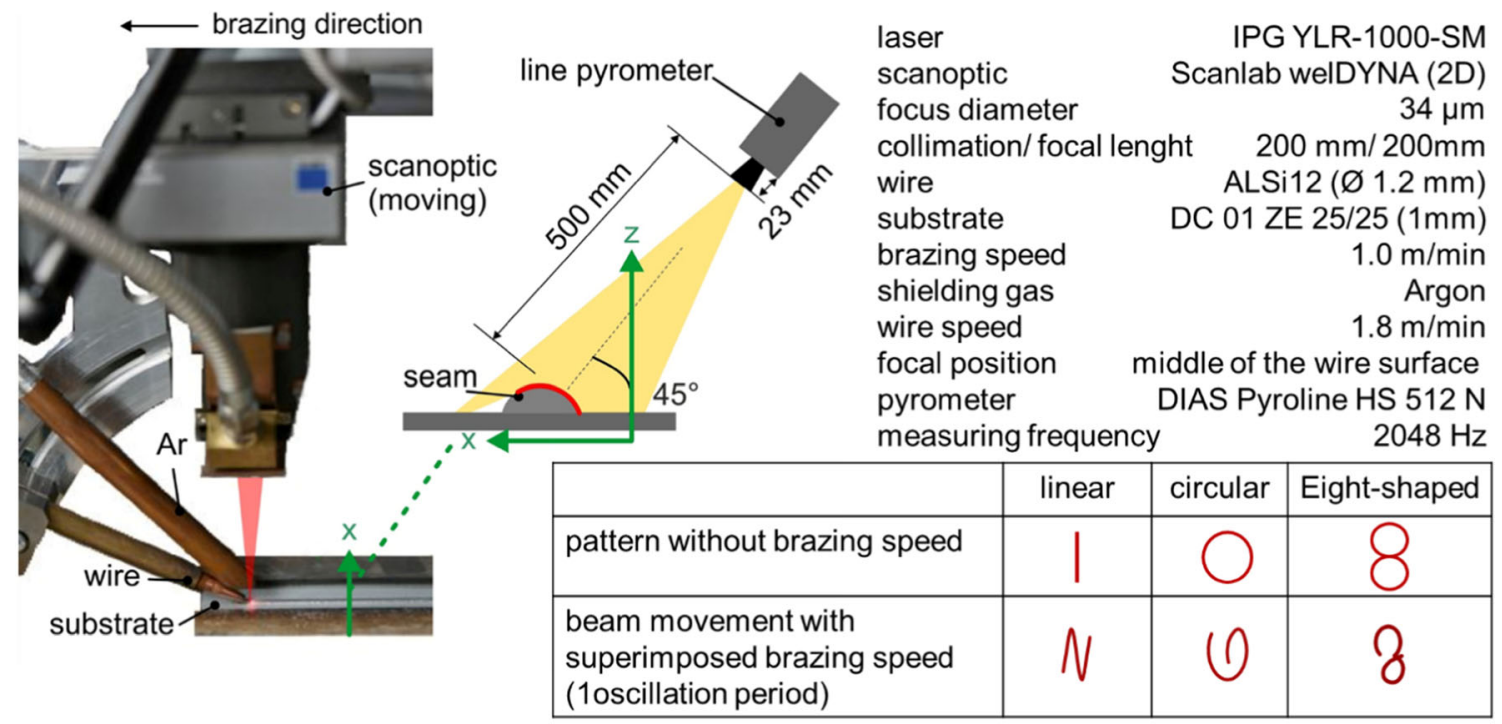

Henze 2019

BIAS ID 200297

Fig. 3 Setup for the temperature measurements 


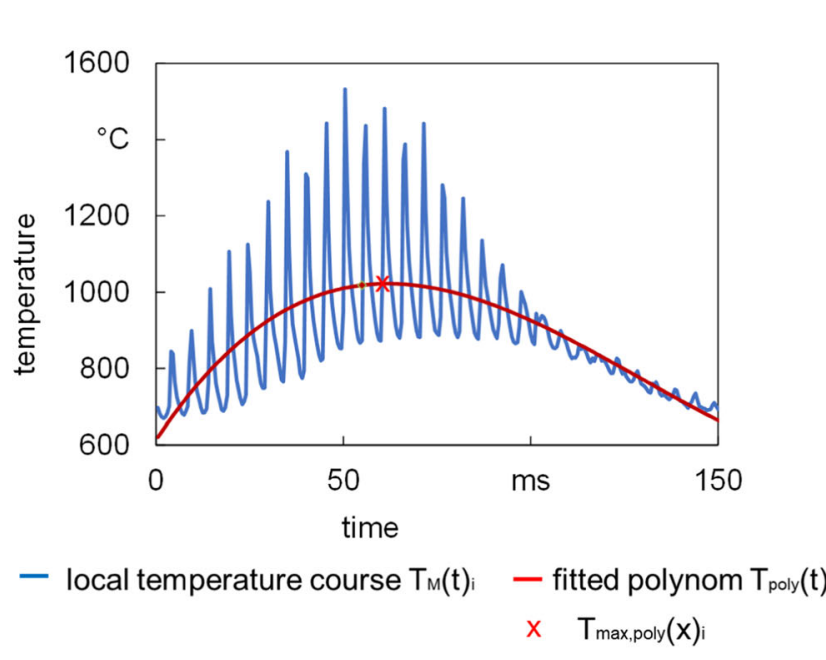

Henze 2020 mean square deviation:

$$
\begin{aligned}
& T_{M S D}(x)_{i}=\sqrt{\frac{\sum\left(T_{M}(t)_{i}-T_{\text {poly }}(t)_{i}\right)^{2}}{m}} \\
& \text { m: number of measurement points }
\end{aligned}
$$

$\begin{array}{lr}\text { laser } & \text { IPG YLR-1000-SM } \\ \text { scanoptic } & \text { Scanlab welDYNA (2D) } \\ \text { wire } & \text { ALSi12 }(\varnothing 1.2 \mathrm{~mm}) \\ \text { substrate } & \text { DC 01 ZE 25/25 }(1 \mathrm{~mm}) \\ \text { brazing speed } & 1.0 \mathrm{~m} / \mathrm{min} \\ \text { laser power } & 470 \mathrm{~W} \\ \text { wire speed } & 1.8 \mathrm{~m} / \mathrm{min} \\ \text { oscillation pattern } & \text { eight- shaped } \\ \text { oscillation width } & 1.2 \mathrm{~mm} \\ \text { oscillation frequency } & 200 \mathrm{~Hz} \\ \text { pyrometer } & \text { DIAS Pyroline HS } 512 \mathrm{~N} \\ \text { measuring frequency } & 2048 \mathrm{~Hz} \\ \text { adjusted emissivity } & 0.3 \\ & \text { BIAS ID } 200298\end{array}$

Fig. 4 Example for a local temperature-time curve with the corresponding fitting polynomial and the maximum temperature of the polynomial

more than the linear and eight-shaped oscillation patterns, indicated by the blue temperature areas between the repetitive red temperature areas.

Figure 8 shows the temperature-time curve and fitted polynomial for an exemplary sample with laser beam line oscillation. The deviations between the polynomial and the temperature-time curve are larger than for the measurement without oscillation (cf. Fig. 6). The illustrated temperaturetime curve is located across the maximum measured temperature $T_{\mathrm{M}, \mathrm{Max}, \mathrm{i}}$ of the entire measurement. It shows repeating temperature peaks. The local temperature-time curves of all samples with beam oscillation show these repeating temperature peaks. The local temperature fluctuations that are up to $900 \mathrm{~K}$. The temporal frequency of the temperature fluctuations matches the adjusted oscillation frequency. The temperature differences tend to decrease slightly with increasing oscillation frequency.

Figure 9 shows the values of the temperature ratio $R_{\text {quo, },}$ of the polynomials across the $\mathrm{x}$-direction. The asymmetry of the curves results from the orientation of the pyrometer which had an angle of $45^{\circ}$ to the sample surface. The illustrated values are the average values and the standard deviations of the three measurements per parameter set. The curve for the measurements without oscillation is steeper than for the measurements
Fig. 5 Measurement of the local temperature profile; the values are detected in relation to a constant emissivity of 0.3

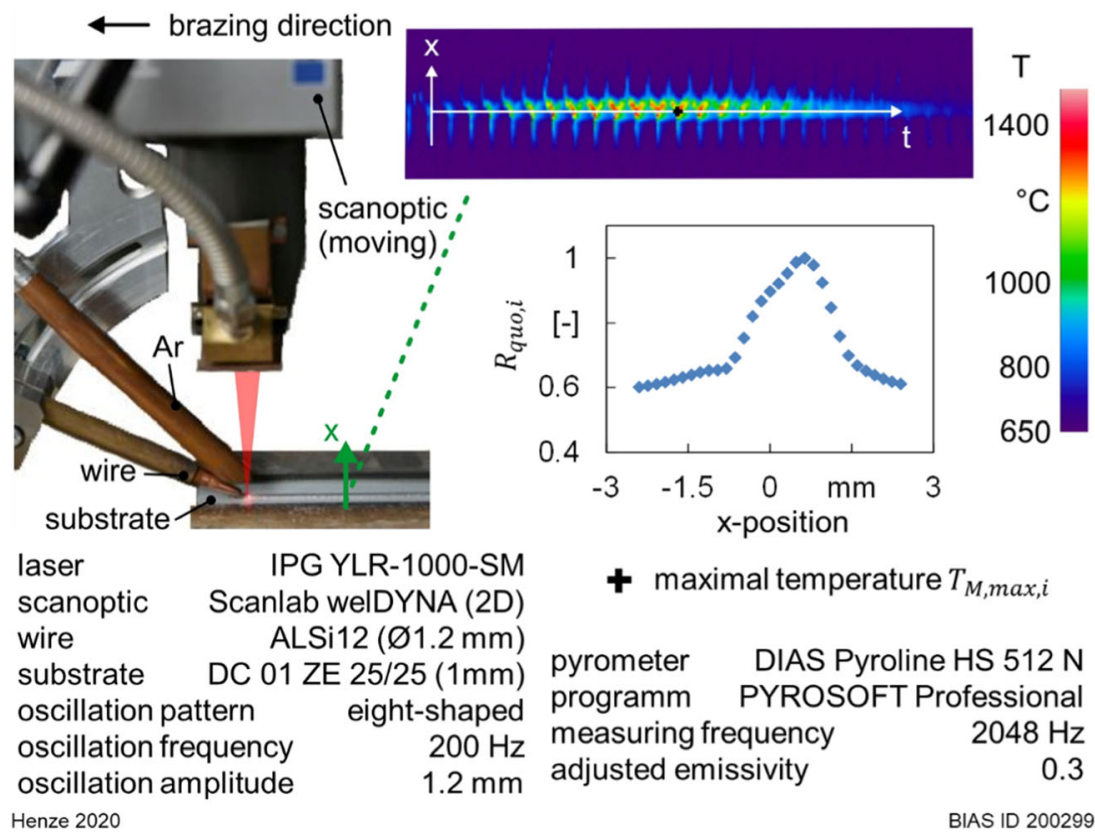


Table 2 Overview of the different steps of the evaluation of the temperature measurements

\begin{tabular}{|c|c|c|c|}
\hline Level & Measurement result & $\begin{array}{l}\text { Corresponding } \\
\text { figure }\end{array}$ & Factors \\
\hline $\begin{array}{l}\text { Single x-position of a single sample } \\
\text { measurement }\end{array}$ & Local temperature-time curve and polynomial & Fig. 4 & $T_{M}(t)_{i}, T_{M, \max , i}, T_{p o l y}(t)_{i}$ \\
\hline $\begin{array}{l}\text { All x-positions of a single sample } \\
\text { measurement }\end{array}$ & Evaluation of the temperature field for one sample & Fig. 4, Fig. 5 & $\begin{array}{l}T_{\text {max }, \text { poly }}(x)_{i}, T_{M S D}(x)_{i} \\
R_{\text {quo }}(x)_{i}\end{array}$ \\
\hline All x-positions of all samples & $\begin{array}{l}R_{\text {quo }}(x) \text { and } T_{\mathrm{MSD}}(x) \text { for the different oscillation } \\
\text { parameters }\end{array}$ & Fig. 9 & $\begin{array}{l}T_{\max , \text { poly }}(x)=\sum_{i=1}^{n} T_{\text {max }, \text { poly }} \\
\quad(x)_{i}, \\
R_{q u o}(x) \\
T_{M S D}(x)=\sum^{n} T_{M S D}(x)_{i}\end{array}$ \\
\hline Per parameter set & Key factors & Fig. 11, Fig. 12 & $\overline{T_{\mathrm{MSD}}} \overline{R_{\text {quo }}^{i=1}}$ \\
\hline
\end{tabular}

with oscillation. For the samples with oscillation, the circular oscillation has the widest area of high temperature ratios, while the linear oscillation pattern has the narrowest.

\section{Discussion}

The repeating temperature fluctuations of the measurements with oscillation had local temperature differences of several $100 \mathrm{~K}$. The highest temperatures were measured at the position of the laser spot whereas afterwards the temperature decreased significantly. The measurements without oscillation had clearly flatter local temperature fluctuations. The appearance of repeating temperature peaks is caused by the multiple local passes of the laser beam by combining a high oscillation frequency with a significant lower brazing velocity. The number of multiple local laser passes depends on the ratio of oscillation frequency and brazing speed, the oscillation pattern and the oscillation size. The temperature differences resulted from the typical high temperature gradients of keyhole processes [5]. The localised energy input caused a high temperature in the keyhole with a high temperature gradient in the vicinity. Therefore, the temperature is significantly higher near the laser beam and decreases after the laser pass by heat conduction and convection in the melt pool. The increase of the oscillation frequency at constant brazing velocity increased the number of local laser passes and thus decreased the period of time between them (time interval). This decreased the time for the local cooling by heat conduction which decreased the range of the temperature fluctuations. However, the applied oscillation frequencies were not high enough for the compensation of the temperature fluctuations being generated by the keyhole formation.

The circular oscillation pattern had lower maximum temperatures and more decreasing temperatures between the laser passes, but it also had the largest temporal expansion of high temperatures transversal to the brazing direction. This behaviour is caused by the average beam velocity and the
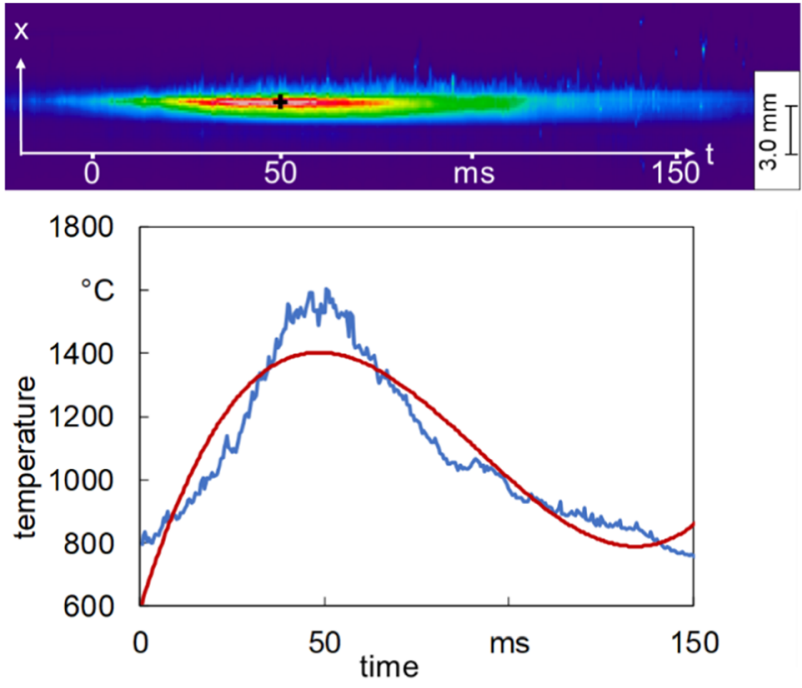

$$
\begin{aligned}
& +\quad \text { maximal temperature } T_{M, \max , i} \\
& -T_{\text {poly }}(t)_{i} \quad T_{M S D}(x)_{i}=83 \mathrm{~K} \\
& -T_{M}(t)_{i}
\end{aligned}
$$

laser scanoptic

IPG YLR-1000-SM collimation/ focal lenght $200 \mathrm{~mm} / 200 \mathrm{~mm}$ wire ALSi12 (Ø1.2 mm) substrate brazing speed laser power wire speed oscillation pyrometer measuring frequency adjusted emissivity
DC 01 ZE 25/25 $(1 \mathrm{~mm})$

$1.0 \mathrm{~m} / \mathrm{min}$

$470 \mathrm{~W}$

$1.8 \mathrm{~m} / \mathrm{min}$

DIAS Pyroline HS $512 \mathrm{~N}$ $2048 \mathrm{~Hz}$ 0.3

Henze 2020

BIAS ID 200300 


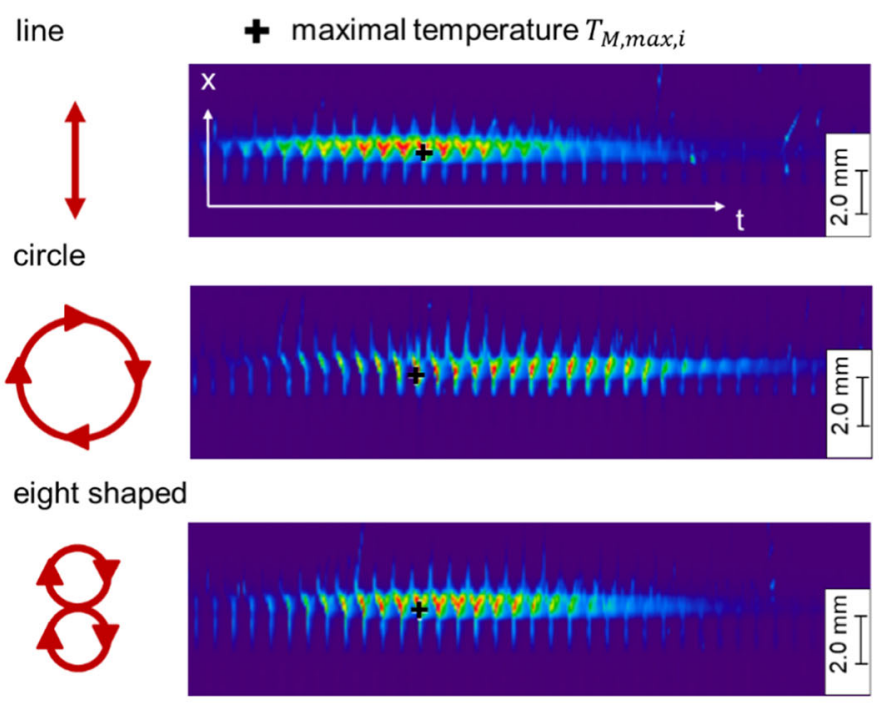

Henze 2020 laser

scanoptic Scanlab welDYNA (2D)

focal diameter $34 \mu \mathrm{m}$

wire

ALSi12 $(\varnothing 1.2 \mathrm{~mm})$

substrate DC 01 ZE 25/25 (1mm)

brazing speed $\quad 1.0 \mathrm{~m} / \mathrm{min}$

shielding gas

laser power

wire speed

oscillation width

oscillation frequency

Argon

$470 \mathrm{~W}$

$1.8 \mathrm{~m} / \mathrm{min}$

$1.2 \mathrm{~mm}$

$200 \mathrm{~Hz}$

pyrometer DIAS Pyroline HS $512 \mathrm{~N}$

measuring frequency $\quad 2048 \mathrm{~Hz}$

adjusted emissivity

0.3

temperature:

$6508001000{ }^{\circ} \mathrm{C} \quad 1400$

BIAS ID 200301

Fig. 7 Measurement results for the three different oscillation patterns at an oscillation width of $1.2 \mathrm{~mm}$ and an oscillation frequency of $200 \mathrm{~Hz}$ at an emissivity of 0.3

geometrical expansion of the circular movement (cf. Fig. 10). This oscillation pattern offers a high average beam velocity and the largest geometrical expansion of all oscillation patterns. A high-beam velocity results in a short local interaction time and therefore a low local heat input, which leads to lower maximum temperatures, as depicted in [18]. The special eightshaped oscillation pattern has the same average beam velocity, but it also has turning points which resulted in lower local beam velocities and therefore higher time-averaged power densities and higher temperatures. The large geometrical expansion leads to a higher expansion of the heated area and therefore distance between the laser positions which extend the cooling process between the laser passes. The large geometrical distance also results in a larger temporal expansion of high temperatures because the laser passes the observed region sooner and leaves later than in the other oscillation patterns.

To rate the different oscillation parameters and the samples without oscillation, the mean values for the mean square deviation $T_{\mathrm{MSD}, \mathrm{x}}$ and the temperature ratios $R_{\mathrm{quo}, \mathrm{x}}$ were calculated across a defined width $x_{1}$ of the measurement (cf. Fig. 11). The results are evaluated referring to their homogeneity. The ideal homogenous temperature-time curve is assumed as a smooth polynomial local temperature-time curve over time in combination with a constant temperature over the width (and therefore a high temperature ratio), as illustrated in Fig.
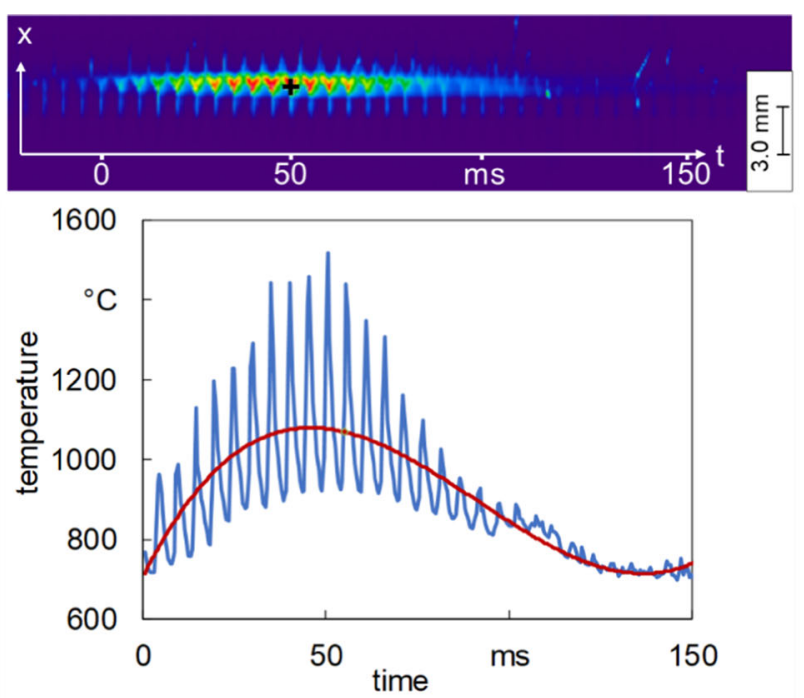

Henze 2020

$$
\begin{aligned}
& + \text { maximal temperature } T_{M, \max , i} \\
& -T_{\text {poly }}(t)_{i} \quad T_{M S D}(x)_{i}=101 \mathrm{~K} \\
& -\quad T_{M}(t)_{i}
\end{aligned}
$$

laser scanoptic wire substrate laser power brazing speed wire speed oscillation pattern oscillation frequency oscillation width pyrometer measuring frequency adjusted emissivity
IPG YLR-1000-SM

Scanlab welDYNA (2D)

ALSi12 (Ø1.2 mm)

DC 01 ZE 25/25 (1mm) $470 \mathrm{~W}$

$1.0 \mathrm{~m} / \mathrm{min}$

$1.8 \mathrm{~m} / \mathrm{min}$

line

$200 \mathrm{~Hz}$

$1.2 \mathrm{~mm}$

DIAS Pyroline HS $512 \mathrm{~N}$ $2048 \mathrm{~Hz}$ 0.3

Fig. 8 Temperature measurement across the maximum measured temperature and the fitted polynomial for a sample with laser beam line oscillation 


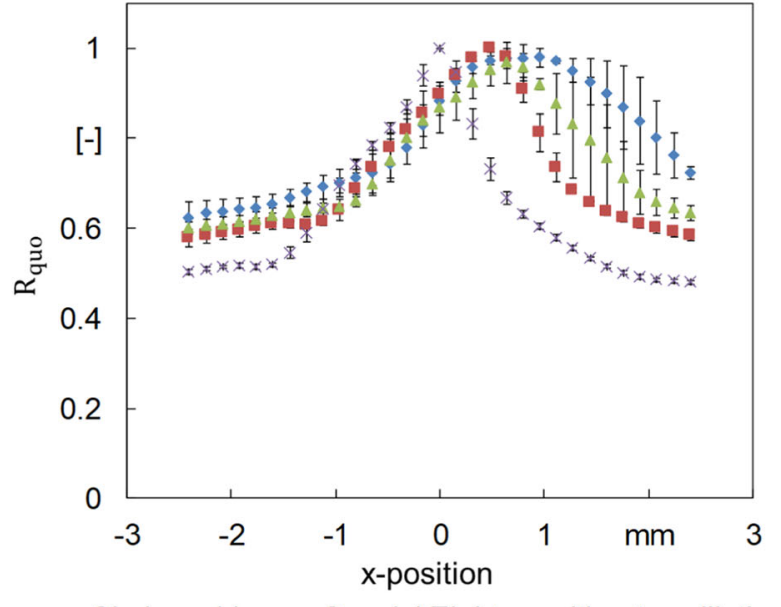

- Circle - Line $\triangle$ Special Eight $\times$ without oscillation
$R_{\text {quo }}(x)=\frac{T_{\max , \text { poly }}(x)}{T_{\max , \text { poly }}}$

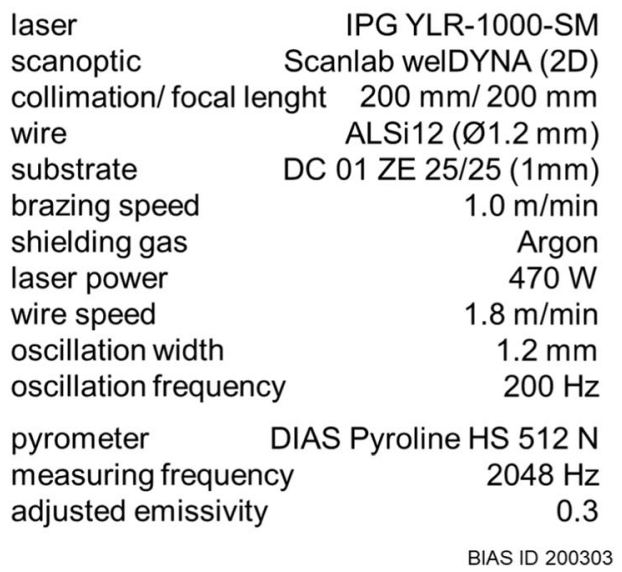

origin of the $x$-axis $(x=0)$ is positioned at the local temperature-time curve with the maximum measured temperature $T_{\mathrm{M} \text {,max }}$

time. The mean square deviation between the polynomial and the local temperature-time curve decreases with increasing frequency, because of the decreasing of the temperature peaks. This decreases the differences between the polynomial and the measured temperature-time curve. The homogenisation increases with increasing frequency. Therefore, it could be assumed that substantially higher oscillation frequencies are necessary to obtain a more homogenous temperature field. The applied two-dimensional oscillation patterns, namely, the circular and special eight-shaped oscillation, cause more homogenous temperature distributions across the cross section, demonstrated by a higher $\overline{R_{\text {quo }}}$, than the linear oscillation pattern. The highest values of $\overline{R_{\text {quo }}}$ were observed for the circular-pattern. This implies that oscillation patterns with constant beam velocities have more homogenous temperature fields, as suspected from the results of Wang et al. [19]. Turning points of the laser beam during oscillation lead to higher local energy inputs and therefore local temperatures. Thus, the homogeneity of the temperature distribution is lower in comparison with movements without turning points.

direction but an unsteady curve of the local temperature over

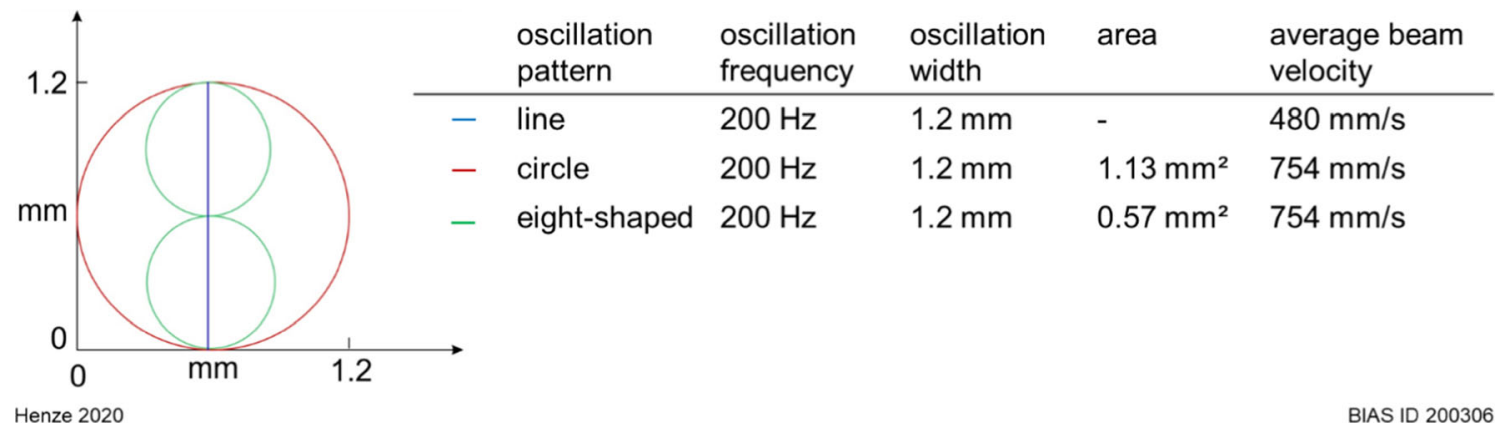

Fig. 10 Geometrical expansion of the three applied oscillation strategies with the calculated average beam velocity at an oscillation width of $1.2 \mathrm{~mm}$ and an oscillation frequency of $200 \mathrm{~Hz}$ 
ideal temperature course

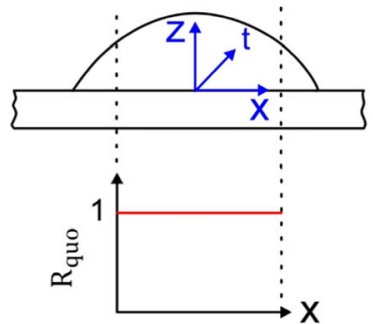

$\mathrm{T}_{\text {max,poly }}(x)=$ const $\rightarrow \overline{\mathrm{R}_{\text {quo }}}=1$

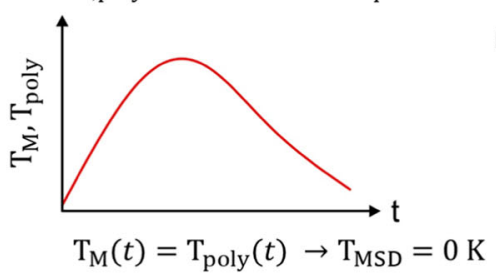

Henze 2020 real temperature course
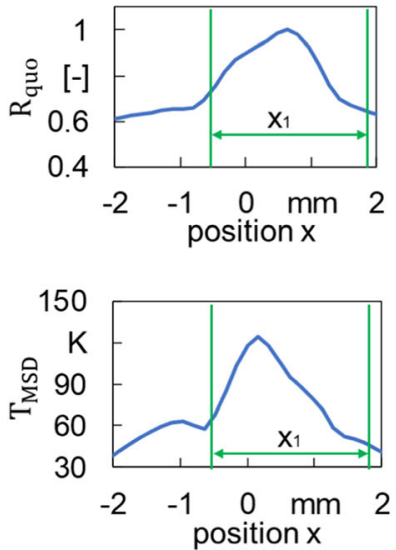

$\overline{\mathrm{R}_{\mathrm{quo}}\left(\mathrm{x}_{1}\right)}<1 \overline{\mathrm{T}_{\mathrm{MSD}, \mathrm{i}}\left(\mathrm{x}_{1}\right)}>0$ laser scanoptic

wire

substrate

laser power

oscillation pattern

oscillation frequency

oscillation width

pyrometer DIAS Pyroline HS $512 \mathrm{~N}$

measuring frequency

emissivity
IPG YLR-1000-SM

Scanlab welDYNA (2D)

ALSi12 (Ø1.2 mm)

DC 01 ZE 25/25 (1mm)

$470 \mathrm{~W}$

special-eight

$200 \mathrm{~Hz}$

$1.2 \mathrm{~mm}$

$2048 \mathrm{~Hz}$

0.3

Fig. 11 Calculation of the rating parameters

BIAS ID 200304

The height of the temperature fluctuation decreases when increasing the frequency but only slightly. The tested oscillation frequencies were not sufficient for the formation of a complete homogenous temperature field. Substantially higher frequencies would, therefore, be necessary. The applied scan optic was not able to apply significantly higher frequencies by using the applied oscillation strategies and widths (= size of the pattern).

\section{Conclusions}

The influence of the laser beam oscillation on the temperature field in laser brazing with keyhole formation has been analysed. Adjusting the oscillation frequency and the oscillation pattern modifies the local temperature-time curve. The results were evaluated according to the homogeneity of the temperature field on the seam surface which has been characterised by two novel key factors.

On the basis of this study, it can be concluded for keyhole brazing with beam oscillation that:

- The oscillation pattern mainly influences the temperature ratio $\overline{R_{\text {quo }}}$ which quantifies the temperature distribution transversal to the brazing direction by varying the local beam velocity and the area of heat input.

- The oscillation frequency mainly influences the mean square deviation $\overline{T_{\mathrm{MSD}}}$ which quantifies the temporal

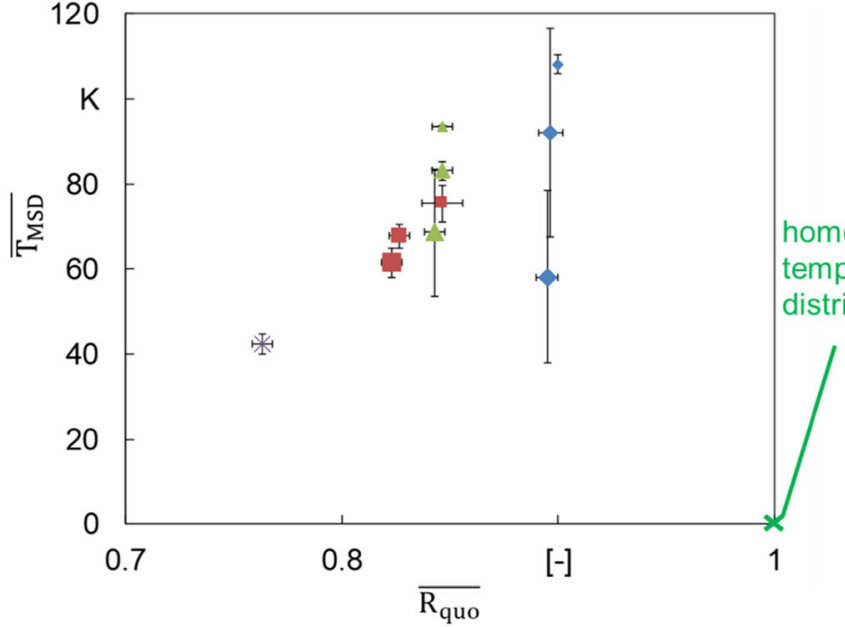

Henze 2020 oscillation frequency:

\begin{tabular}{|c|c|c|c|}
\hline & $100 \mathrm{~Hz}$ & $200 \mathrm{~Hz}$ & $300 \mathrm{~Hz}$ \\
\hline line & $\bullet$ & $\bullet$ & $\square$ \\
\hline circle & $\bullet$ & $\bullet$ & \\
\hline eight & $\Delta$ & $\Delta$ & $\triangle$ \\
\hline
\end{tabular}

$X$ without oscillation

$\begin{array}{lr}\text { laser } & \text { IPG YLR-1000-SM } \\ \text { scanoptic } & \text { Scanlab weIDYNA (2D) } \\ \text { wire } & \text { ALSi12 (Ø1.2 mm) } \\ \text { substrate } & \text { DC 01 ZE 25/25 (1mm) } \\ \text { pyrometer } & \text { DIAS Pyroline HS } 512 \mathrm{~N} \\ \text { measuring frequency } & 2048 \mathrm{~Hz} \\ \text { adjusted emissivity } & 0.3\end{array}$

BIAS ID 200305

Fig. 12 Comparison of the properties of the temperature distributions of the different tested parameters using the developed key parameters for the homogeneity of the temperature field 
local temperature-time curve by varying the time interval between the local laser passes.

- A circular oscillation pattern with a high oscillation frequency results in more homogenous temperature fields on the seam surface during keyhole brazing than line and eight-shaped patterns or lower frequencies.

Authors' contributions Not applicable.

Funding Open Access funding enabled and organized by Projekt DEAL. The research was funded by the DFG-Deutsche Forschungsgemeinschaft (engl.: German Research Foundation, project number: 326408602). The "BIAS ID" numbers are part of the figures and allow the traceability of the results with respect to mandatory documentation required by the funding organisation.

Availability of data and material Data is available at the institution from the authors.

\section{Compliance with ethical standards}

Conflict of interest The authors declare that they have no conflicts of interest.

Code availability Not applicable.

Open Access This article is licensed under a Creative Commons Attribution 4.0 International License, which permits use, sharing, adaptation, distribution and reproduction in any medium or format, as long as you give appropriate credit to the original author(s) and the source, provide a link to the Creative Commons licence, and indicate if changes were made. The images or other third party material in this article are included in the article's Creative Commons licence, unless indicated otherwise in a credit line to the material. If material is not included in the article's Creative Commons licence and your intended use is not permitted by statutory regulation or exceeds the permitted use, you will need to obtain permission directly from the copyright holder. To view a copy of this licence, visit http://creativecommons.org/licenses/by/4.0/.

\section{References}

1. Mathieu A, Pontevicci S, Viala J-c et al (2006) Laser brazing of a steel/aluminium assembly with hot filler wire $(88 \% \mathrm{Al}, 12 \% \mathrm{Si})$. Mater Sci Eng A 435-436:19-28. https://doi.org/10.1016/j.msea. 2006.07.099

2. Quintino L, Costa A, Miranda R, Yapp D, Kumar V, Kong CJ (2007) Welding with high power fiber lasers - a preliminary study. Mater Des 28:1231-1237. https://doi.org/10.1016/j.matdes.2006. 01.009

3. Lee JY, Ko SH, Farson DF, Yoo CD (2002) Mechanism of keyhole formation and stability in stationary laser welding. J Phys D Appl Phys 35:1570-1576. https://doi.org/10.1088/0022-3727/35/13/320

4. Hügel H, Graf T (2009) Laser in der Fertigung. Vieweg+Teubner, Wiesbaden (in german)

5. Wang H, Shi Y, Gong S (2006) Numerical simulation of laser keyhole welding processes based on control volume methods. J
Phys D Appl Phys 39:4722-4730. https://doi.org/10.1088/00223727/39/21/032

6. Radel T, Woizeschke P, Vollertsen F (2016) Keyhole brazing- an approach for energy-efficient brazing by using the deep penetration effect. In: DVS Berichte Band 325, vol 325, pp 302-306

7. Gatzen M, Radel T, Thomy C, Vollertsen F (2014) Wetting behavior of eutectic Al-Si droplets on zinc coated steel substrates. J Mater Process Technol 214:123-131. https://doi.org/10.1016/j. jmatprotec.2013.08.005

8. Quintino L, Assunção E (2013) 6 - Conduction laser welding. In: Katayama S (ed) Handbook of laser welding technologies. Woodhead Pub, Philadelphia, pp 139-162

9. Schultz V, Cho W-I, Woizeschke P et al (2017) In: Overmeier L, Reisgen U, Ostendorf A, Schmidt M (eds) Laser deep penetration weld seams with high surface quality. Lasers in Manufacturing Conference (LiM) 2017

10. Heller K (2017) Analytische Temperaturfeldbeschreibung beim Laserstrahlschweißen für thermographische Prozessbeobachtung. Dissertation, Herbert Utz Verlag GmbH; Graf, T. (Ed.), Universität Stuttgart (in german)

11. Mathieu A, Matteï S, Deschamps A, Martin B, Grevey D (2006) Temperature control in laser brazing of a steel/aluminium assembly using thermographic measurements. NDT E Int 39:272-276. https://doi.org/10.1016/j.ndteint.2005.08.005

12. Bagavathiappan S, Lahiri BB, Saravanan T, Philip J, Jayakumar T (2013) Infrared thermography for condition monitoring - a review. Infrared Phys Technol 60:35-55. https://doi.org/10.1016/j.infrared. 2013.03.006

13. Wikle HC, Kottilingam S, Zee RH et al (2001) Infrared sensing techniques for penetration depth control of the submerged arc welding process. J Mater Process Technol 113:228-233. https:// doi.org/10.1016/S0924-0136(01)00587-8

14. Khan MA, Madsen NH, Goodling JS, Chin BA (1986) Infrared thermography as a control for the welding process. Opt Eng 25: 256799. https://doi.org/10.1117/12.7973908

15. Abuhamad M (2011) Spektrale Information in der Thermographie. Dissertation, Universität des Saarlandes, NaturwissenschaftlichTechnische Fakultät (in german) https://doi.org/10.22028/D29122709

16. Bernhard F (2014) Handbuch der Technischen Temperaturmessung. Springer, Berlin Heidelberg (in german)

17. Leitner M, Leitner T, Schmon A, Aziz K, Pottlacher G (2017) Thermophysical Properties of liquid aluminum. Metall Mater Trans A 48:3036-3045. https://doi.org/10.1007/s11661-0174053-6

18. Henze I, Woizeschke P (2019) Keyhole brazing with twodimensional laser irradiation patterns. In: Reisgen U, Zäh M, Schmidt MF, Rethmeier M (eds) Proceedings of Lasers in Manufacturing Conference (LiM) 2019

19. Wang L, Gao M, Zhang C, Zeng X (2016) Effect of beam oscillating pattern on weld characterization of laser welding of AA6061-T6 aluminum alloy. Mater Des 108:707-717. https://doi.org/10.1016/j. matdes.2016.07.053

20. Matmatch (2020) EN 10130 Grade DC01 skin passed. https:// matmatch.com/materials/minfm33714-en-10130-grade-dc01-skinpassed. Accessed 07 Jan 2020

21. novasens Sensortechnik Heuer (2020) Emissionsgradtabelle für die Infrarot Temperaturmessung. https://www.novasens.de/wpcontent/uploads/Emissionsgradtabellenovasens.pdf. Accessed 07 Jan 2020

Publisher's note Springer Nature remains neutral with regard to jurisdictional claims in published maps and institutional affiliations. 